This is a self-archived version of an original article. This version may differ from the original in pagination and typographic details.

Author(s): Valtonen, Katariina; Seppänen, Ville; Leppänen, Mauri

Title: Government Enterprise Architecture Grid Adaptation in Finland

Year: 2009

Version: Accepted version (Final draft)

Copyright: (c) 2009 by The Institute of Electrical and Electronics Engineers, Inc.

Rights: In Copyright

Rights url: http://rightsstatements.org/page//nC/1.0/?language=en

Please cite the original version:

Valtonen, K., Seppänen, V., \& Leppänen, M. (2009). Government Enterprise Architecture Grid Adaptation in Finland. In Proceedings of the 42th Hawaii International Conference on System Sciences (HICCS-42), January 5-8, Waikoloa, Big Island, Hawaii.

https://doi.org/10.1109/hicss.2009.232 


\section{Government Enterprise Architecture Grid Adaptation in Finland}

\author{
Katariina Valtonen \\ University of Jyväskylä \\ katariina.valtonen@jyu.fi
}

\author{
Ville Seppänen \\ University of Jyväskylä \\ ville.seppanen@titu.jyu.fi
}

\author{
Mauri Leppänen \\ University of Jyväskylä \\ mauri@cs.jyu.fi
}

\begin{abstract}
In government, support for strategic political steering, administrative and cross-sectoral development, and integration of processes and systems can be sought out of enterprise architecture (EA) planning. To facilitate this, a proper EA method covering essential government levels is needed. A constructive case study has been carried out to create an adaptation model of Finnish government EA (GEA) grid. The study builds on general principles of method adaptation and observations about GEA method engineering and its pilot adaptations in Finnish State Administration. The model presents systematic guidelines for situational GEA grid adaptation and reuse in Finnish State administration. The model supports GEA grid adoption as a strategic tool for planning and management of organizational change. It facilitates prioritization of government goals, communication and commitment among government actors, and implementation of government interoperability.
\end{abstract}

\section{Introduction}

Current trends of public administration (PA) reforms are directed towards electronic services (eServices) and managerial administrative models, such as New Public Management (NPM) [8]. For planning and implementing them, enterprise architecture tools are commonly applied [7]. Enterprise Architecture (EA) is a central notion used to align strategies, processes, information, systems and technologies of an enterprise [15]. To structure, organize and guide EA planning, a number of EA frameworks and methods have been suggested (e.g., [28], cf. a review in [15]). An EA grid signifies here an EA framework in the matrix form.

PA as the context of EA planning sets specific requirements and constraints on a manner in which an EA method is applied [19]. For government use, EA methods are defined locally or adapted from wellknown frameworks [6][7]. An EA grid is in a key position in this adaptation, since it structures the EA descriptions and guides the EA planning process.
In Finland, as part of the Interoperability Development Programme (IDP), a method for government EA (GEA) planning [26] was engineered by adapting some existing EA frameworks [28][5][16] for PA. The method is composed of a large conceptual EA grid, a general-level process model, and normative instructions to apply the grid and description models within it. The GEA method is generic, i.e., it has to be adapted before applying in each development environment. We made observations in the GEA method engineering project and two pilot adaptation projects in Finnish PA. Based on findings from these projects and a review of relevant literature, we designed an adaptation model of the GEA grid deployment in Finnish government organisations.

The aim of the paper is to present (a) a description of EA method adaptation carried out in Finland, (b) an analysis of principles underlying the EA grid adaptation, as well as (c) the GEA grid adaptation model (Geagam) and benefits of using the model.

The remainder of the paper is structured into eight sections. In Section 2, we define basic concepts related to method adaptation and EA frameworks. In Section 3, we introduce the Finnish State administration as the context of applying the GEA method. In Section 4, we describe the GEA method engineering project and findings from its adaptation in two pilot organizations. Section 5 outlines our research methodology. In Section 6, we bring out the principles underlying the GEA grid adaptation and present the GEA grid adaptation model (Geagam). Section 7 discusses the benefits of the GEA grid adaptation. The paper ends with a summary and conclusions.

\section{Previous research}

No method as such is suitable, but it needs to be adapted for situational needs. Method adaptation means the customization or tailoring of a method in a way which makes it more suitable for a domain, an organization, or a project [23]. There are two main approaches to method adaptation. In the first approach, an adapted method is engineered by collecting compo- 
nents from known methods and by integrating them into a customized array of models and techniques (e.g. [4]). In the second approach, a single method, called a base method, is selected and then customized, for instance, by dropping out some of its components, and by enhancing it with new components [21]. Both of these approaches seem to be used in EA method adaptation for PA (see [6] and [7]).

An EA method consists of a framework, a modeling process, techniques, models and roles (cf. [22]). Here, we are particularly interested in the EA frameworks. Many of the ideas of modern EA owe to the pioneering work of John Zachman [44] whose EA framework is in the form of a two-dimensional grid. Zachman's framework has got a number of successors and has affected the development of government EA methods too [6].

Through an EA framework, the complex structure of an enterprise can be modeled from different aspects [3]. According to Shah and Kourdi [36], the framework helps to identify the scope of the architecture and structure its elements in architectural layers and dimensions. The framework ensures the consistency of the produced descriptions [22]. It also guides EA planning and development process (e.g., EAG [31][32], Spewak [36]). A suitable specification of a framework is thus of uttermost importance [22]. We use the term EA grid to refer to an EA framework which is in the matrix form. In the EA literature, the dimensions (or columns) of EA grids are more or less fixed, often corresponding to the viewpoints of business architecture (BA), information architecture (IA), systems architecture (SA) and technology architecture (TA) (e.g., [16]). The layers (or levels), however, are still subject to debate.

Layered EA frameworks help in representing various aspects in different models and levels of abstraction [3]. Based on their analysis of work on enterprise architectures, Braun and Winter [3] argue that four design layers have to be differentiated. These include strategy, organizational, application, and software component layers. However, they also note that all the layers need not be found in all approaches, but the layers should be in accordance with the purpose. Malan and Bredemeyer [24] discuss the architectural levels of scope (those of enterprise, domain, application, and component) that help in focusing the architectural decision-making. Agreeing with Bass, Clements and Kazman [2] they conclude that architectural decisions should be deferred to the lower levels in the architectural hierarchy, if it is possible to develop and implement a requirement there [24]. Our focus in the study has been on adapting of architectural levels for different government purposes.

Although there is no agreement, which layers should constitute the essence of EA, it is common to apply an approach where strategic positioning is followed by organizational processes and structures, and finally by information systems [43]. For example, EA Management Grid (EAG, [16]) suggests the description levels of (1) an enterprise, (2) its domains and (3) subsequent systems, in order to support the implementation of strategic goals. An EA planning process based on the EAG framework [31] flows from the strategic enterprise level towards concrete domain and systems levels. At each level, EA descriptions and consequent decisions sharpen towards more focused, concrete and detailed design issues.

The EA frameworks and methods are too generic to be applied as such. According to the survey of national EA work [6], 89\% of the governments have defined their EA frameworks locally, mostly based on some of the generic ones. For example, USA's FEA framework (FEAF) [5] has been inspired by Zachman's and Spewak's ones [6]. Further, for FEAF, concepts to be applied using a variety of architectural frameworks and methodologies in federal government are introduced in [10]. However, as far as we know, adaptation models inside the public infrastructure of a country have not been published largely. Therefore, we propose an example of an EA framework adaption model.

\section{Finnish State administration}

We introduce shortly the Finnish State administration, in order to clarify the context of EA method adaptation. State administration includes about 12 ministries, with ca. a hundred bureaus and agencies in State central administration [27]. Most of the ministries have regional and local offices too operating solely on a regional or local basis (e.g., local register offices) [27].

In Finland, there have been New Public Management related reforms since 1987 [40]. In NPM, the political steering is strategic by nature, which means that ministers are subjects and the administration is the object of steering [40]. Decentralization frees managers to manage, wherefore ministers are free to concentrate on broad, strategic decisions guiding the operational execution [40].

Tiili [40] has analyzed the strategy practices of Finnish State administration between 1995-2006. Government Program (GP, [12]) consists of Government vision, and collections of strategic goals of administrative branches [40]. Since 1995, government strategy specifications have explicated the projects needed to implement GP [40]. Thereafter, program management has been carried on since 2003, to enhance the means for steering and monitoring the implementation of the GP, especially in matters requiring cross-sectoral cooperation [30]. Government strategy specifications 
have thereafter contained outlined policy programs and their consequent legislative plans [29]. Policyprograms comprise projects with their measures and responsibilities [13].

Although these strategic practices have brought rigor to political decisions, there have been few signs of strategic political steering in Finnish Government since 1995 [40]. Strategy documents are characterized as collections of strategic agendas of each ministry, while there has neither been the will, nor the courage among Government members to prioritize the projects, and to make selections [40]. Projects in strategy specifications lack equal interest politically: GP has either had small issues that are too concrete, or goals that are too general to be strategic [40]. GP was also considered only as a legitimization of what the ministries were already doing [40]. However, new guidelines insist relevant information: 'In the process of promoting and monitoring the GP, the Government shall only be provided with information necessary to make decisions ensuring the materialization of the GP' [29].

To support the strategic political steering, the GEA grid adaptation model (Geagam) aims to promote EA descriptions in such a way that the information and strategic goals presented for ministers shall be relevant and produced in a systematic way. This enhances the prioritization and selection of the most important strategic goals, and outlining of the vision of entire government operation instead of just justifying the current state of administration.

\section{CASE: EA method adaptation for PA}

In autumn 2006, Interoperability Development Program (IDP) was launched in the Ministry of Finance in Finland to implement a government policy decision on the development of IT management [25]. Its challenging tasks were, par excellence, to engineer a government EA (GEA) method and a GEA governance model. Here, we focus on the GEA method engineering (described also in [41][17]) and its pilot adaptations in two State central agencies.

\subsection{GEA method engineering project}

The GEA method engineering project (Geamep) group consisted of representatives of Finnish State administration (different ministries and their agencies), a municipality, a university, and the liable consultancy, all bringing their expertise on different fields to the project. The work in the project comprised five tasks: (1) the selection of a suitable EA method or EA methods, (2) the adaptation of the EA methods for Finnish PA, (3) making a user manual for the resulting GEA method, (4) applying the GEA method to a small-scale case and thus producing an exemplar document of the method use, and (5) planning and describing a high level target architecture. The project group worked in 15 workshops from late autumn 2006 until April 2007.

Out of current EA methods, TOGAF [28], FEAF [5], and EAG [16] were found to best meet the requirements set for the new method (cf. [17]). The GEA method was engineered by integrating components of these. The first version was published in June 2007 [26]. The method is composed of a conceptual framework (GEA grid), a process model with stepwise, normative instructions, and an array of description models.

The GEA grid is structured by three description levels and four architectural dimensions (Table 1). The description levels are: PA, domains (e.g., a branch of administration) and sub-domains (e.g., a government agency). For the description of the target state EA, the domain level of the GEA grid was denoted as a cluster [26], i.e., a network of organizations, organized around a common goal. Sub-domains in that case were, respectively, denoted as subareas of the development goal of the cluster [26]. The EA viewpoints correspond to four common sub-architectures: BA, IA, SA and TA (cf. [16][5]). The sub-architectures describe, for instance, organization, services and processes of BA, and strategic data warehouses, information assets and vocabularies of IA. IS portfolios are typical descriptions of SA, whereas technology policies, standards and reference models are typical ones of TA [26].

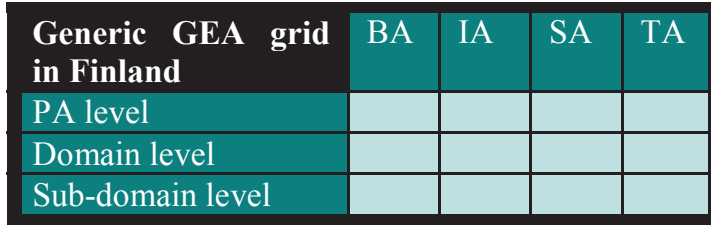

Table 1: Overview of the GEA grid.

The GEA method is to be applied situationally [26]. This implies, for instance, that a suitable approach to the situation at hand is selected. If the process-driven approach is selected, the first steps are taken to develop BA and IA focusing on services, processes and information. In the system-driven approach, the EA development may start with describing current systems and how they might be harmonized or integrated.

The GEA process model [26] is composed of three phases. In the first phase, the scope of the EA work is to be defined, descriptions of the current state EA collected, needs for the change explored, the vision of the target state outlined, and the development project established. The second phase is to produce primary designs of selected viewpoints and levels concerning the target state EA. Stakeholders are then to be identified, 
suitable description models selected, issues affecting the EA at hand analyzed, the target state EA modeled, the target state plans reconsidered, and the defect analysis carried out. The last phase is to make a transition plan of the implementation projects, to assess and prioritize them, and to distribute the outcomes to the stakeholders [26].

\subsection{GEA grid adaptation in two agencies}

The Finnish GEA method has been used in pilot projects in two State administration agencies in 2007 [34][39]. Road Administration (RA) under the Ministry of Transport, plans, maintains, and develops highway networks in cooperation with its regional State offices and authorities of other means of transport. State Treasury (ST), under the Ministry of Finance, produces administrative support services for the entire government. In the projects, the agencies applied the newly established GEA method and the GEA governance model (both produced in IDP). In the following, we shortly describe the GEA grid adaptation in the agencies, and analyze emerged adaptation bottlenecks.

RA has been developing EA for many years, and it has been considered as one of the forerunners in public administration EA work in Finland. Until the pilot project, the work had been conducted without a common method. This had led to a situation where EA products were inconsistent and, in some cases, incompatible among the divisions. The work had also been characteristically driven by IT department with only slight engagement of business managers. Some of the main goals of the project in RA were to collect the dispersed efforts together, to increase the involvement of the business representatives, and to reduce the number of overlapping information systems.

The GEA grid adaptation in RA (Table 2) features the original architectural viewpoints of the GEA grid. The description levels (enterprise, domain and systems levels) correspond, for example, to [24],[16] and [3]. The topmost level describes the organization as a whole from strategic, business-driven, and abstracted point of view. The domain level stands for organizational divisions or other operational units of RA. The systems level features the lowest level of abstraction describing, for example, design patterns and reference architectures of systems. The architectural decisions and principles, demarcated in Ministry of Transport and Communication and Government, were given as boundary values of the RA grid.

In ST, the main goal of the project was to establish and design a common architecture for eServices delivery. A sketch of the current state EA was to be produced as grounds for the requirements specification of the eServices platform. In addition, the GEA grid was to be adapted for further ST use.

\begin{tabular}{|l|l|l|l|l|}
\hline GEA grid in RA & BA & IA & SA & TA \\
\hline Road Administration & & & & \\
\hline Domains & & & & \\
\hline Systems of a domain & & & & \\
\hline
\end{tabular}

Table 2: Overview of the GEA grid in RA.

The GEA grid adaptation process in ST was quite straightforward, due to the fact that the adaptation was not the main goal of the project. The description levels were adopted according to the original GEA grid (see Table 3). The domain level was renamed according to the corresponding ministry, and the sub-domain as ST. In our opinion, this way of adaptation lacks the support of EA process as described in [31]. The resulted grid does not fully facilitate the decomposing of strategic plans as subsequent domain and systems implementation. In their post-project feedback, ST suggested a grid which resembled the grid adapted in RA, though.

\begin{tabular}{|l|l|l|l|l|}
\hline GEA grid in ST & BA & IA & SA & TA \\
\hline State administration & & & & \\
\hline Ministry of Finance & & & & \\
\hline State Treasury & & & & \\
\hline
\end{tabular}

Table 3: Overview of the GEA grid in ST.

As seen, the pilot adaptations produced two different outcomes of the GEA grid (cf. Tables 2 and 3). This is partly due to the fact that ST and RA had different liable consultancies in their projects. One consultancy was the same who was involved in the development of the GEA method, but for another the GEA method was new. The GEA method documentation neither indicated nor instructed the adaptation of the GEA grid. There was no direct communication between the two pilot projects either. Unawareness of expected adaptation practices could be sensed in the project with a consultancy with no previous experience of the newly established GEA method. Thus, the consultancy had to ponder the adoption of the method much more, in order to mentally fix it with their EA concepts. They encountered questions of choosing proper description models and relevant abstraction levels thereof. They arrived at exploiting also descriptions of their own, in addition to the GEA method descriptions. RA and ST grids yielded thus diversified description models compared to each others.

At RA, the chosen description levels support the decomposition EA planning into development domains. The description levels of EAG [31] are taken into use. ST took the given GEA grid more or less for granted, partly since the emphasis of the project was on 
the eServices platform. An inconsistency with respect to the adaptation of the description levels is remarkable, even more since both of the agencies are in a comparable position in State central administration.

\section{Research Methodology}

Our research has been made as a constructive case study [20] following the design science approach [14]. The goal was to create a model of the Finnish GEA grid adaptation, based on practical work of GEA method engineering and adaptation as well as current literature on method adaptation, EA, and government reforms. Finnish state administration as a complex adaptive system (GEA as CAS, cf. [19]) provided a challenging environment with approximately 130 organizational actors, and a deep hierarchy of administrative levels.

The first author was acting as a participatory observer at the project workshops of the GEA method engineering. Discussions were written down as field notes, tape recorded at most times, and transcribed and summarized. The second author was observing the pilot adaptations of GEA method in RA and ST. These authors attended several events of IDP. The documents of IDP were also available during the study in a shared workspace of Ministry of Finance.

During 2007, discussions with IDP managers and participants confirmed us of the need of the GEA method adaptation guidelines, thus triggering the work to create the GEA grid adaptation model (Geagam, [42]). The work was commented at meetings of the steering group of the Finnish Enterprise Architecture Research (FEAR) project. In addition, the model was validated through stakeholder reviews by key actors of IDP, the consultancies (TietoEnator Oyj, CapGemini) and the State administration representatives (Ministry of Finance, State Treasury, Road Administration).

\section{GEA grid adaptation model (Geagam)}

\subsection{Underlying principles}

The GEA grid adaptation model has been built on five main principles driven from literature and our experience in IDP. In the following, they are expressed as requirements for the GEA grid adaptation.

(1) The GEA grid has to support a totality of organizational actors and service providers whether of public, private, or 3rd sector. A very task of EA methods is to reduce the complexity [22] of PA [19] resulting from numerous actors with various, possibly conflicting or overlapping goals at several administrative levels (central, regional and local). An additional dimen- sion emerges with privatization of public service production (cf. [8][18]). For situations like this, no single, fixed, neither too generic GEA grid can tackle the EA modeling needed.

(2) The GEA grid has to support systematic transformation towards a target state GEA. A current state EA describes existing business practices and ICT infrastructures [35] of PA. A target state EA is a strategic expression of will about a desired future state [35]. Following a trend towards modeling business-lines instead of single organization architectures [9], the target state architecture of Finnish State administration aims at cross-sectoral, seamlessly integrated eServices [25] to avoid sector-driven administrative silos. Policyprograms in Finland present a new strategic, political tool to manage these cross-sectoral development goals [29] as presented in Section 3. However, strategic political tools alone can be seen inadequate to support these kinds of changes. Systematic methodical tools are needed.

(3) The adaptation of description levels has to reflect a rational and centrally advised decomposition into coherent architectural entities. In Section 2 we concluded that architectural dimensions (BA, IA, SA, TA) have established themselves, whereas the description levels of EA frameworks still vary. The adaptation of the description levels is problematic if it is not centrally advised (cf. Section 4.2.). GEA grid adaptation guidelines have to advise decomposing of the totality properly and coherently. The adaptation of the description levels have to reflect these guidelines for each architectural entity subject to EA planning.

(4) Use of the GEA grid has to support EA planning at administrative management level. One of the main objectives stated in the Geamep group was to produce a GEA grid that could be adapted for different operational purposes. Three major purposes were expressed. First, the GEA grid should support planning of common, centralized services (e.g., the centralized financial management of State administration). Second, it should provide help in planning of cross-sectoral processes (CSP) of clusters of organizations. Third, the GEA grid should be adaptable into the use of various organizational actors (e.g. a university, an agency).

(5) The GEA grid has to support analyzing and directing a whole-of-an-administration. Besides EA planning of centralized services, CSPs, and organizational actors at central, regional or local levels (cf. organization-specific adaptation [23]), the GEA grid should support the strategic political steering of an administration. Decision making in PA, occurring at the global level, is quite different from that occurring at the local level [19]. The global level aims at balancing the overall interests of many different local agencies [19]. For example, whole-of-government and 
whole-of-ministry EA planning should identify and present relevant strategic issues for ministers.

\subsection{Types of use as two grid types}

In our adaptation model we divide the use of the GEA grid in two types: for 1) strategic use to enhance political steering, and for 2) operational use to enhance management of an administrative unit.

In strategic use, the GEA grid is to model and direct a whole-of-an-administration (e.g., a whole-ofgovernment, a whole-of-ministry). The parts of a large administrative entity are summed up and analyzed through a strategic grid type. The strategic grid type sums parts of a large administrative entity in a relevant way. It consists of the description levels of government levels underneath the administration to be steered. The entire picture of the status quo will be summed up through gathering and analyzing EA descriptions of the parts. The future target architecture will be further outlined to eliminate overlaps, to reorganize the structure, to form new coalitions for cross-sectoral goals, and to share responsibilities for different actors.

In operational use, the GEA grid guides modeling of an administrative unit concerning its operational domains and subsequent information systems. An operational grid type presents an EA grid adapted in an administrative unit of the government hierarchy in a communicative and relevant manner.

In the EA literature, there seems not to be an EA artifact suitable for the strategic grid type. For the operational grid type, we propose the EA management grid (EAG) by Hirvonen and Pulkkinen [16][31][32] adapted in the government hierarchy. It was utilized in the pilot adaptation in RA with promising experience. We push this idea further by adapting the EAG in other administrative management purposes.

\subsection{GEA grid in State administration}

Based on the aforementioned principles and types of use, we have engineered a GEA grid adaptation model (Figure 1). It is composed of four grids illustrating the strategic and operational use. The grids share the established architectural viewpoints of BA, IA, SA, and TA. Each grid contains three description levels for its purpose. Albeit the Geagam seems to result in a bunch of grids in usage, the contents of different grids can be of two main options, that of the strategic or the operational type.

State administration grid exemplifies the strategic use of the GEA grid. The operational use is exemplified with EA grids for a centralized solution, a cluster and an organizational actor. The arrows signify the positioning of the three operational grids in respect to the topmost State administration entity, thus reflecting the decomposition of the totality for EA planning. The contents of the operational grids are explicated in the legend. The patterns in the cells of the State administration grid are not explained, since the grid analyzes and sums more government parts in summary than those that can be illustrated by the three operational grid instances. It should be noted that the number of actual grids depends on the situation at hand. The four grids in Figure 1 have been derived for the needs of Finnish state administration from the Geamep discussions (cf., [41]) and the overall research case setting. In the following, we describe the grids and their use in more detail.

The State administration EA grid illustrates the strategic grid type for the highest purpose. The grid user collects information of branches and agencies thereof, yielding the global picture of the "as is" State administration architecture. This work should be facilitated by a centralized repository of architectural descriptions, as repeatedly argued in the Geamep group. The State administration grid is to support communication between the highest officials and Government, where the latter decides on future directions. Thus, the produced descriptions have to be conceptual and abstract, where excessive details are to be obscured.

The operational grid types present grids with a narrower scope. The EA grid for centralized solutions guides the planning and implementation of a common, centralized service (e.g., a central register, a central unit for support services, etc.). The EA grid for a cluster is used to develop and implement common goals of a cluster. For example, there is a lack of customerdriven process architectures in child welfare. Different officials of child welfare should consider the continuum of a child's life and plan the service process among different service providers accordingly. The uppermost cluster level of the grid could include strategic descriptions of the cluster (e.g., goals, agreements, and commitments). The EA grid for an organizational actor (whether an agency, an enterprise or other organization) guides the strategic planning and management to take into account the organizational environment.

In the State administration grid, the description level of branches of administration and the subsequent level of agencies present recognized pressures and challenges, conclusive maps of core business functions, information assets, technologies and constraints etc. Architectural pictures of different branches, and parts thereof, are compared with each others, and their shared and specific needs with possible overlaps and conflicts are revealed. Based on this information, essential shortcomings are recognized and presented at the highest level. The state administration level con- 
tains models and descriptions that bring value for Government.

The optional level of clusters in the State administration grid can be utilized in the formulation of the target state EA parallel with capturing of the current branches. New co-operative organizational forms can be designed to by-pass the current state administrative silos. Plans of adding, deleting or adapting a branch, or parts thereof, can be made to establish a more effective form of organization or to define virtual forms of organization (e.g., in [33]). The target state GEA provides, for example, future business-lines, clusters thereof, information assets and ICT strategies with wellgrounded transition plans. State administration EA planning yields further requirements to branches, organizations and clusters.

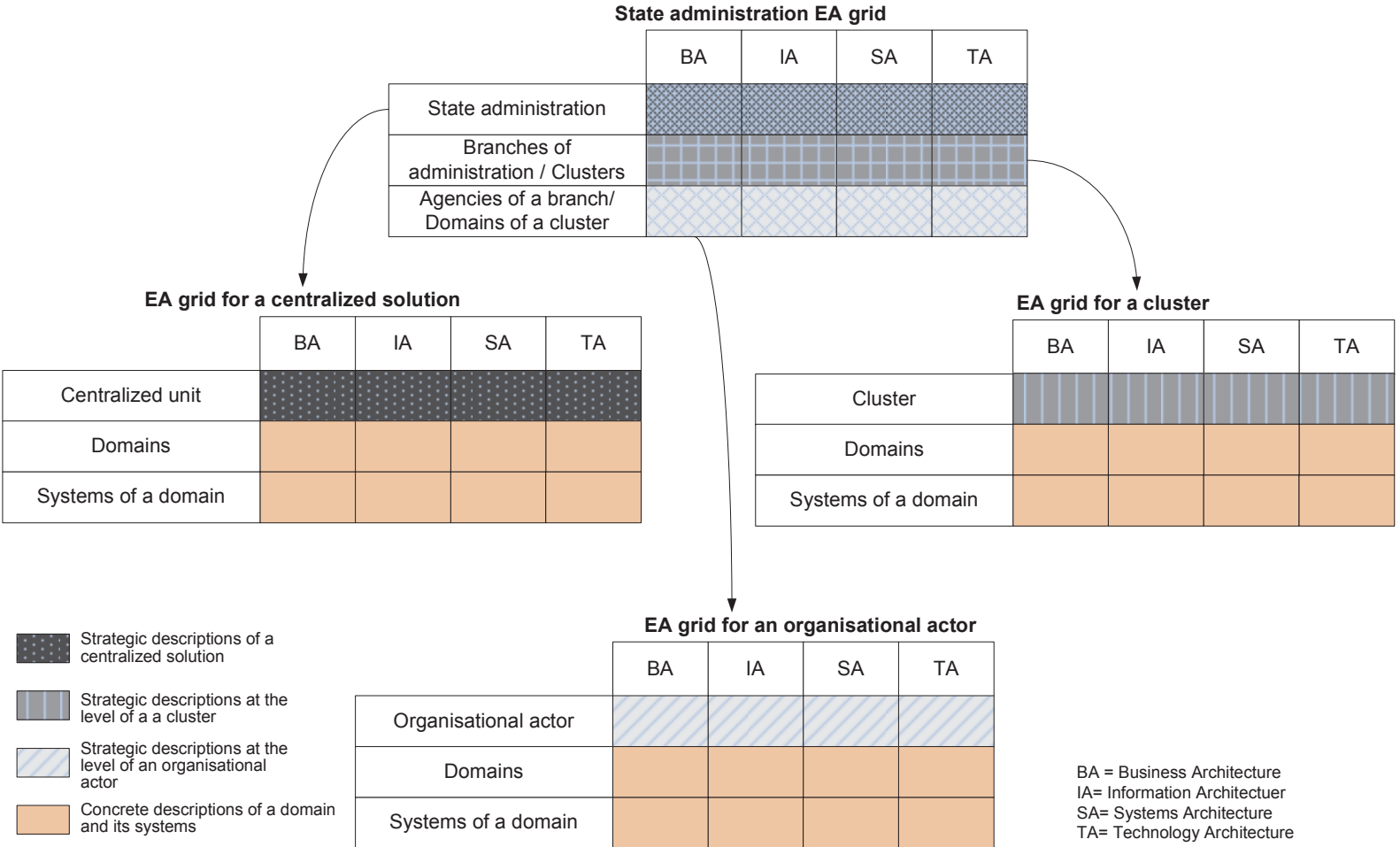

Figure 1. GEA grid adaptation model (Geagam). Examples of strategic and operational use.

In the operational grids for centralized services, clusters or organizations, the description levels of EAG (i.e. enterprise, domain and systems levels, [31]) are adapted. These are equipped with suitable description models. Typically, at the top levels of a centralized unit, a cluster or an organization (Figure 1) future core services are considered in the light of chosen technologies [31]. Examples of suitable descriptions are target state process and services maps, list of central registries, information portfolio, IS portfolio, and current and future technologies [26][34][32]. Moreover, the boundary values (e.g., standards, definitions of policies) of the superior authority must definitely be taken into account [34][26]. Examples of the domain level models are various process and stakeholder descriptions, and models on information carried in the processes (e.g., a processinformation matrix) [34]. At the level of systems of a domain, the models describe, for example, systems requirements, data structures, design structures and platforms of IT systems [34] [32].

To support the application of the Geagam we have constructed a procedure [42] which guides the instantiation of the GEA grid into a concrete EA framework in an agency according to Geagam. It is beyond the space limit of this paper. Geagam has been crafted particularly for the adaptation of the GEA grid wherefore it is an integral part of it. The Geagam exemplifies adaptation of a layered EA grid in a hierarchical set of organisations where the aim is to enhance development of inter-organisational services too. The inherent ideas in the Geagam model can thus be applied with other layered EA grids.

\section{Benefits of Geagam}

Geagam presents a structure of State administration EA planning descriptions and decisions, offering (1) a managerial tool to plan and manage adminis- 
trative changes coherently. The purpose of EA planning is to understand the future goals, whereafter their implementation is more straightforward [1]. During the transition, the structure of State administration may be diversiform, since the old and new operational structures may appear simultaneously. Through a coherent method and adaptation, the complexity of the change can be managed.

(2) Geagam helps perceiving State administration as a whole and presenting the "big picture" of it. The current state architecture and the target state architectures need to be captured before organizational change can be implemented. Geagam helps to discern the descriptions of different levels and dependencies between them. When the information about strategic goals and projects is at a comparable level of abstraction, unessential details are obscured. Overlapping or conflicting goals and doubled efforts can thus be recognized more easily. Systematic production and structuring of EA descriptions reveals relevant information and pinpoints the strategic goals of political interest impartially. This enhances the prioritization and selection of the most important strategic goals, and the outlining of the government vision.

To implement the change, (3) Geagam can help the transformation process in many ways. During the stakeholder review of the model it appeared that a responsibility of organizing some development efforts (e.g., for a centralized solution) had been delegated to a single agency. Instead of just naming an agency as an implementer, $(3 a)$ an adapted grid can help to recognize the form of organization accordingly to the designed EA plans. Furthermore, (3b) communication and commitment among organizational actors is enhanced. Presenting strategic plans openly based on well-understood whole-of-an-administration architecture promotes discussion and commitment. Moreover, the adaptation model offers a coherent terminology for adaptation. Using the grid types given in Geagam, the adaptation of an EA grid is easier than starting off with a clean slate. The grid types can be applied at different contexts more easily than that of only one original grid in [26]. Thus, (3c) Geagam relieves the reuse of the GEA method bringing synergy gains.

(4) By using Geagam the overall interoperability is enhanced through methodical consistency. Without adaptation guidelines there is a risk that different adaptations of the GEA method are not compatible and consistent. This may lead to unnecessary communication problems. The GEA method offers description templates to enhance syntactical comparability [26]. Geagam guides decomposing an entity into architectural sub-entities for EA development. When the decomposition is formed by common guidelines, the comparison of the parts of the architecture is easier. This further facilitates the planning of future goals (e.g., planning of CSPs).

(4a) Geagam supports interoperability across the levels of hierarchy. When national criteria for wide band network implementations were missing, it resulted undesirably in many diversified regional implementations [38]. Alignment of global and local governments is thus to be supported by methodical tools. Vertical interoperability is an ability to exchange information from one level to an upper or a lower level of the hierarchy. The EA planning of an administration and of its underlying units are dependent on each others. Ministries pay attention to the State level boundaries, such as government program, strategy specifications and budget frames, taking them into account in the planning of ministry-wide strategies. Policies on standards, technology usage, and architectural principles are concerns of head officials of ministries. These interests are to be met through EA considerations. For actors underneath the ministries the information of the topmost levels is to be transferred systematically.

(4b) Geagam supports different co-operative forms and interoperability across sectors. Crossagency architectures and public-private partnerships are encouraged by adapting the GEA grid for clusters. Geagam supports a systematic way to implement cross-sectoral policy programs (cf. Section 3) for which there are no ministries as implementers [29], but which require a virtual organization [33] or other strong means of coordination.

Geagam is a theoretical construct derived from the literature and the practical projects. As far as we know, no such an adaptation model has been explicitly presented. (5) The model is abstract but advises the practical work at hierarchical domains of PA. It applies to a variety of situations. In the context of merging several municipalities, for instance, strategic methods are essential. For the planning of the organizational change, EA planning can be organized using respective grid types of the Geagam. They can be applied to support gathering strategic information for the municipal board and administration (strategic grid). The planning of centralized support functions, new cross-sectoral service processes, and merged spheres of authority can be structured by using the three operational grid types respectively.

\section{Conclusions}

This paper introduced a government EA grid adaptation model (Geagam). The model was built on the knowledge of Finnish government, observations 
about government EA (GEA) method engineering and its pilot adaptations, and literature. The model is based on strategic and operational grid types used to advise political steering and administrative management, respectively. The previous type was exemplified by a State administration grid to support communication between highest state administration officials and Government. The operational type was suggested for three general purposes, for EA planning of a centralized solution, a cluster or any administrative organizational actor. The Geagam is an inherent part of the GEA grid.

Our model of GEA grid adaptation provides a novel tool for strategic political steering and management of strategy implementation. It supports GEA grid adoption as a strategic tool and facilitates the prioritization of government goals, implementation of government interoperability, and communication and commitment among government actors. The model presents systematic guidelines for situational GEA grid adaptation and reuse thus supporting consistency of adaptation.

Implementation of a common method and its adaptation practices across a large variety of organizations is challenging. Geagam has to be placed in action and applied "in situ" to be subjected to testing. and validation. Moreover, Geagam should be enlarged with guidelines of how to adapt the process, roles and description models of the GEA method. The method offers a large toolkit of possible description models, where situational data of EA development use cases would be of benefit for both research and practice.

New laws on consolidation of municipalities (e.g., [10]) have been passed in Finland, which makes architectural planning important also in municipal administration. The municipalities produce similar statutory services, and deploy information systems in relatively similar processes. Needs for harmonizing emerge. Also strategic political steering in local government is subject to stronger expectations in Finland [40]. In these efforts, a means such as Geagam would be of great benefit to support adaptation of the government EA grid and EA planning. The present job of the first author in a Finnish town which is merging with 5 other municipalities, should enable the applying the Geagam in real situation and gaining of more evidence on the applicability of Geagam.

\section{Acknowledgements}

The authors thank their research colleagues, the members of the projects and several other people in Finnish PA for valuable ideas, discussions and com- ments. The research was funded by the ValtIT research project, FEAR project and COMAS Graduate School.

\section{References}

[1] F.J. Armour, S.H. Kaisler, and S.Y. Liu, "Building an Enterprise Architecture Step by Step", IT Professional, July-August 1999, pp. 31-39.

[2] Bass, L., P. Clements, and R. Kazman, Software Architecture in Practice, Addison-Wesley, 1997.

[3] Braun C., and R. Winter, A Comprehensive Enterprise Architecture Metamodel and Its Implementation Using a Metamodeling Platform, Workshop in Klagenfurt, GIEdition Lecture Notes, 2005, 64-79.

[4] S. Brinkkemper, M. Saeki, and F. Harmsen, "Metamodelling Based Assembly Technique for Situational Method Engineering", Information Systems 24(3), 1999, pp. 209-228.

[5] Chief Information Officer Council, A Practical Guide to Federal Enterprise Architecture, v. 1.0, February 2001. http://www.gao.gov/bestpractices/bpeaguide.pdf

[6] Christiansen, P.E., and J. Gotze, (2006) International Enterprise Architecture Survey - Trends in Governmental Enterprise Architecture on a National Level, http://www.easurvey.org/06_easurveyreport_ver01.pdf

[7] P.E. Christiansen, and J. Gotze, "Trends in Governmental Enterprise Architecture: Reviewing National EA Programs - Part 1", Journal of Enterprise Architecture 3(1), 2007, pp. 8-18

[8] A. Cordella, "E-government: Towards the eBureaucratic Form?", Journal of Information Technology 22(3), 2007, pp. 265-274.

[9] Executive Office of the President of the US, FEA Consolidated Reference Model Document, v. 2.3, 2007.

[10] FEA Practice Guidance. www.whitehouse.gov/omb/ egov/documents/FEA_Practice_Guidance_Nov_2007.pdf.

[11] Finlex, Law on Local Government Reform 9.2.2007/169, in Finnish, 2007.

http://www.finlex.fi/fi/laki/ajantasa/2007/20070169

[12] Finnish Government, Government Program 2008. http://www.valtioneuvosto.fi/hallitus/hallitusohjelma/en.jsp

[13] Finnish Government, Government Policy Programmes at Vanhanen's Cabinet 2003-2007. valtioneuvosto.fi/tietoarkisto/politiikkaohjelmat/en.jsp

[14] A. Hevner, S. March, J. Park, and S. Ram, "Design Science in Information Systems Research", MIS Quarterly 26(1), 2004, pp. 75-105. 
[15] Hirvonen, A., M. Pulkkinen, J. Ahonen, and V. Halttunen, The Gap between Strategies and Implementation Methodic Support for EA Projects as a Bridge, IBIMA 2003, Cairo, 2003.

[16] Hirvonen, A., and M. Pulkkinen, A Practical Approach to EA Planning and Development: the EA Management Grid, BIS’04, Poznan, Poland, 2004, 284-302.

[17] Hirvonen, A., M. Pulkkinen, and K. Valtonen, Selection Criteria for Enterprise Architecture Methods, ECIME conference 2007, Montpellier, France, 2007.

[18] Janssen, M., and A. Cresswell, Enterprise Architecture Integration in E-government, 38th Hawaii International Conference on System Sciences, 2005.

[19] Janssen, M., and G. Kuk, A Complex Adaptive System Perspective of Enterprise Architecture in Electronic Government, HICSS-39, Hawaii, 2006.

[20] Järvinen, P., On Research Methods, Opinpaja Oy, Tampere, 2003.

[21] F. Karlsson, and P. Ågerfalk, "Method Configuration: Adapting to Situational Characteristics While Creating Reusable Assets", Information and Software Technology 46(9), 2004, pp. 619-633.

[22] Leist, S., and G. Zellner, Evaluation of Current Architecture Frameworks, SAC'06, Dijon, France, 2006, 23-27.

[23] Leppänen, M., An Ontological Framework and a Methodical Skeleton for Method Engineering, Jyväskylä Studies in Computing 52, University of Jyväskylä, Dissertation thesis, 2005 .

[24] R. Malan, and D. Bredemeyer, "Less is More with Minimalist Architecture", IT Pro Sept/Oct, 2002, pp. 46-48.

[25] Ministry of Finance, Government Policy Decision on the Development of IT Management in State Administration, Public Management Department Publications 3c/2006, Finland, www.vm.fi/publications.

[26] Ministry of Finance, The GEA Method, User manual 1.0, 29.6.2007, in Finnish, Referred 15.6.2008, http://www.hare.vn.fi/upload/Asiakirjat/12260/104939 Lo ppuraportti_Liite_02_Arkkitehtuurimenetelmä.pdf

[27] Ministry of Finance, Functioning of PA, 2008, http://www.suomi.fi/suomifi/english/in focus/functioning of_public_administration/index.html

[28] OpenGroup, The Open Group Architecture Framework (TOGAF) Version 8.1 "Enterprise Edition", referred on 4.12.2006, http://www.opengroup.org/togaf

[29] Prime Minister's Office, Renewed Model of Programme Management, Policy Programmes in Government Work, Prime Minister's Office Publications 13/2006, In Finnish, Edita Prima Oyj, Helsinki, 2006.
[30] Prime Minister's Office, Government Strategy Document 2007, Prime Minister's Office Publications 4/2008, Helsinki University Print, Helsinki, 2008.

[31] Pulkkinen, M., and A. Hirvonen, EA Planning, Development and Management Process for Agile Enterprise Development, $38^{\text {th }}$ HICSS 2005.

[32] Pulkkinen, M., Systemic Management of Architectural Decisions in Enterprise Architecture Planning. Four Dimensions and Three Abstraction Levels, $39^{\text {th }}$ Annual Hawaii International Conference on System Sciences (HICSS '06), Kauai, Hawaii, 2006.

[33] Punia, D.K., K.B.C. Saxena, Managing Interorganizational Workflows in eGovernment Services. ICEC'04, 2004, 500-505.

[34] Road Administration EA, GEA Method adapted for RA, v. 0.9., 2007. Project document in Finnish.

[35] Schekkerman., J., How to Survive in the Jungle of Enterprise Architecture Frameworks. Creating or Choosing an Enterprise Architecture Framework. Trafford, 2003.

[36] Spewak, Steven H. (1992). Enterprise Architecture Planning: Developing a Blueprint for Data, Applications and Technology, John Wiley \& Sons, Inc, New York.

[37] H. Shah, and M.E. Kourdi, "Frameworks for Enterprise Architecture", IT Professional 9(5), 2007, pp. 36-41.

[38] State Audit Office, Execution of Regional Information Society Projects, Report of Inspection 158/2008, in Finnish.

[39] State Treasury, EA Method for ST, 2007. Project document in Finnish.

[40] Tiili, M., Ministers as Strategic Political Leaders? Strategic Political Steering after NPM Reforms in Finland. Academic dissertation, Acta Politica 34, Department of Political Science, Univerity of Helsinki, 2008.

[41] Valtonen, K., and M. Leppänen, Business Architecture Development at Public Administration - Insights from Government EA Method Engineering Project in Finland. ISD’08 Conference, Pafos, Cyprus 2008.

[42] Valtonen, K., and V. Seppänen, Adaptation and Adoption of Finnish Government EA Method, Public Management Department Publications 4/2008, Ministry of Finance, 29.1.2008. In Finnish, English summary. www.vm.fi/publications

[43] Winter, R., and R. Fischer, Essential Layers, Artifacts, and Dependencies of Enterprise Architecture, EDOCW '06, 2006.

[44] J.A. Zachman, "A Framework for Information Systems Architecture", IBM Systems Journal 26(3), 1987, pp. 276-292. 